\title{
Seawater salt-trapped Pseudomonas aeruginosa survives for years and gets primed for salinity tolerance
}

\author{
Hamouda Elabed ${ }^{1,2}$, Enrique González-Tortuero ${ }^{3}$, Claudia Ibacache-Quiroga ${ }^{2,4}$, Amina Bakhrouf5, Paul Johnston 6 ,
} Kamel Gaddour ${ }^{5}$, Jesús Blázquez ${ }^{2}$ and Alexandro Rodríguez-Rojas ${ }^{6^{*}}$ (I)

\begin{abstract}
Background: In nature, microorganisms have to adapt to long-term stressful conditions often with growth limitations. However, little is known about the evolution of the adaptability of new bacteria to such environments. Pseudomonas aeruginosa, an opportunistic pathogen, after natural evaporation of seawater, was shown to be trapped in laboratorygrown halite crystals and to remain viable after entrapment for years. However, how this bacterium persists and survives in such hypersaline conditions is not understood.

Results: In this study, we aimed to understand the basis of survival, and to characterise the physiological changes required to develop salt tolerance using $P$. aeruginosa as a model. Several clones of $P$. aeruginosa were rescued after 14 years in naturally evaporated marine salt crystals. Incubation of samples in nutrient-rich broth allowed re-growth and subsequent plating yielded observable colonies. Whole genome sequencing of the $P$. aeruginosa isolates confirmed the recovery of the original strain. The re-grown strains, however, showed a new phenotype consisting of an enhanced growth in growing salt concentration compared to the ancestor strain. The intracellular accumulation of $\mathrm{K}^{+}$was elicited by high concentration of $\mathrm{Na}^{+}$in the external medium to maintain the homeostasis. Whole transcriptomic analysis by microarray indicated that 78 genes had differential expression between the parental strain and its derivative clones. Sixty-one transcripts were up-regulated, while 17 were down-regulated. Based on a collection of single-gene knockout mutants and gene ontology analysis, we suggest that the adaptive response in $P$. aeruginosa to hyper-salinity relies on multiple gene product interactions.
\end{abstract}

Conclusions: The individual gene contributions build up the observed phenotype, but do not ease the identification of salinity-related metabolic pathways. The long-term inclusion of $P$. aeruginosa in salt crystals primes the bacteria, mediating a readjustment of the bacterial physiology to growth in higher salt concentrations. Our findings provide a starting point to understand how $P$. aeruginosa, a relevant environmental and pathogenic bacterium, survives to longterm salt stress.

Keywords: Pseudomonas aeruginosa, Gene expression, Salt priming, Long-term stress

\section{Background}

In their natural environments, microbes often have to cope with stressful conditions. The limitation of nutrients, intense competition for resources and a variety of abiotic stresses such as radiation, temperature, $\mathrm{pH}$, oxygen-derived radicals, antibiotics and high osmolarity are commonly experienced by bacteria [1].

\footnotetext{
* Correspondence: a.rojas@fu-berlin.de

${ }^{6}$ Institute of Biology, FreieUniversität Berlin, Berlin, Germany

Full list of author information is available at the end of the article
Reports on the extreme longevity of microbes in salt are controversial [2]. Hypersaline environments have been a significant reservoir for the long-term evolution of specially adapted microorganisms [3]. Additionally, saline environments may aid the survival of microorganisms, protecting them from desiccation by trapping the cells in fluid inclusions, a phenomenon that occurs in salt crystals upon evaporation [4]. Several studies on ancient microbes are consistent with laboratory experiments and studies on other modern surface halite

(c) The Author(s). 2019 Open Access This article is distributed under the terms of the Creative Commons Attribution 4.0 International License (http://creativecommons.org/licenses/by/4.0/), which permits unrestricted use, distribution, and 
deposits, which suggest that microorganisms persist inside fluid inclusions in halite for many year [5-7].

In a previous study, Pseudomonas aeruginosa cells were shown to get trapped in fluid inclusions pockets of saturated brine in laboratory-grown halite crystals and to remain viable after entrapment [5]. The ability of $P$. aeruginosa to colonise and thrive in myriad environments correlates with its relatively large genome and genetic complexity [8]. An exceedingly high number of assigned open reading frames are transcriptional regulators or members of two-component regulatory systems in comparison to other bacteria [9]. This large proportion of regulatory genes also facilitates $P$. aeruginosa adaptability and sensing diverse environmental stresses [8-11]. Potassium is the major intracellular cation in bacteria and plays an important role to maintain homeostasis. In osmotic conditions, bacterial cells accumulate $\mathrm{K}^{+}$by a number of different transport systems that vary in kinetics, energy coupling, and regulation [12].

However, despite advances in the understanding of the immediate response to hyperosmotic shock in $P$. aeruginosa [13], the physiological mechanisms that allow the bacterial persistence in highly saline environments are still poorly understood. Molecular basis of this persistence may be of great interest to both clinical and environmental microbiology. In the present study, we assess the phenotypic and genotypic changes of $P$. aeruginosa ATCC 27853 after 14 years of entrapment in seawater salt crystals to characterise the required physiological changes that allow salt tolerance.

\section{Results}

\section{Evaluation of fitness in different salt conditions}

In this work, we study the effects of long-term incubation in extremely salty conditions on $P$. aeruginosa using microarrays and salt-tolerance assays. After 14 years of inclusion in evaporated seawater (37 g/l of salts), different clones of $P$. aeruginosa were recovered and cultivated. The revitalisation of the culture in nutrient broth at $37^{\circ} \mathrm{C}$ rendered bacterial suspensions that reached an average of $\mathrm{OD}_{600 \mathrm{~nm}}: 0.9 \pm 0.06$, after $48 \mathrm{~h}$ of incubation.
The ancestor strain (T0 or control) and its derivative 48$\mathrm{h}$ clones (T48), did not show significant differences in growth rate when cultured with $\mathrm{NaCl} 8.5 \mathrm{mM}$ (normal concentration of $\mathrm{NaCl}$ in DM medium (Table 1). However, the final OD was significantly higher in the recovered T48 strain. This implies a growth advantage in the stationary phase demonstrating the adaptability of the recovered cells to extremes conditions such as starvation. After the long period in salt crystals, supposing the selection of more adapted mutants, we also cultured the bacteria under increasing concentrations of $\mathrm{NaCl}$. The variants $\mathrm{T} 48$ showed an improved growth rate at concentrations of 250 or $500 \mathrm{mM}$ (Table 1). At $1 \mathrm{M}$, the ancestor strain was not able to grow, whereas T48 clones reached the highest optical density of all conditions (Fig. 1). These first results suggested that T48-derivative clones acquired the ability to thrive in high-salt environments, even at $\mathrm{NaCl}$ concentrations that were restrictive for the original strain. However, no significant differences were found when comparing growth rates $(r)$ between $\mathrm{T} 0$ and $\mathrm{T} 48$ variants at other evaluated $\mathrm{NaCl}$ concentration (Table 1). Moreover, the addition of 100 $\mathrm{mM} \mathrm{KCl}$ to bacterial cultures of the T0 strain, inhibited by $1 \mathrm{M}$ of $\mathrm{NaCl}$, restored the growth of this strain and allowed T48 strain to growth even at $2 \mathrm{M} \mathrm{NaCl}$ (Fig. 2), indicating that growth inhibition not only depends on salt concentration but also on the composition of growth media. The tolerance to $\mathrm{NaCl}$ is then influenced by the level of $\mathrm{KCl}$ or maybe the ability of the cell to control $\mathrm{K}^{+}$ transport. Hence, our expectations were to find the role of $\mathrm{K}^{+}$and $\mathrm{Na}^{+}$transporters or regulators in $P$. aeruginosa to long-term hypertonic conditions. All these observations demonstrate that after incubation of $P$. aeruginosa in seawater crystals for a long period (14 years), the cells adapted and became more tolerant to higher salt concentrations.

\section{Whole genome sequencing after recovery from salt}

To characterise possible genomic adaptations to salt in $P$. aeruginosa, we sequenced five independent clones and the reference strain using a whole genome sequencing

Table 1 Comparison of the growth rate $(r)$ of T0 and T48 variants in DM medium containing different concentrations of sodium chloride: Mann-Whitney $U$ test

\begin{tabular}{llll}
\hline $\mathrm{NaCl}$ concentration & $r$ T0 & $r$ T48 & $P$ value \\
\hline Control $(0.0085 \mathrm{M})$ & $9.875 \times 10^{-4} \pm 9.257 \times 10^{-5}$ & $9.721 \times 10^{-4} \pm 1.454 \times 10^{-4}$ & 0.886 \\
$0.0625 \mathrm{M}$ & $2.126 \times 10^{-3} \pm 6.876 \times 10^{-5}$ & $2.465 \times 10^{-3} \pm 1.644 \times 10^{-4}$ & 0.200 \\
$0.125 \mathrm{M}$ & $3.287 \times 10^{-3} \pm 9.084 \times 10^{-5}$ & $2.268 \times 10^{-3} \pm 3.666 \times 10^{-4}$ & 0.029 \\
$0.25 \mathrm{M}$ & $4.176 \times 10^{-3} \pm 9.661 \times 10^{-5}$ & $0.011 \pm 8.071 \times 10^{-4}$ & 0.029 \\
$0.5 \mathrm{M}$ & $6.585 \times 10^{-3} \pm 1.933 \times 10^{-4}$ & $0.019 \pm 1.933 \times 10^{-4}$ & 0.029 \\
$1 \mathrm{M}$ & $7.658 \times 10^{-3} \pm 2.217 \times 10^{-4}$ & $0.022 \pm 1.463 \times 10^{-3}$ & 0.029 \\
$2 \mathrm{M}$ & $0.030 \pm 1.405 \times 10^{-3}$ & $0.021 \pm 1.404 \times 10^{-3}$ & 0.029 \\
\hline
\end{tabular}



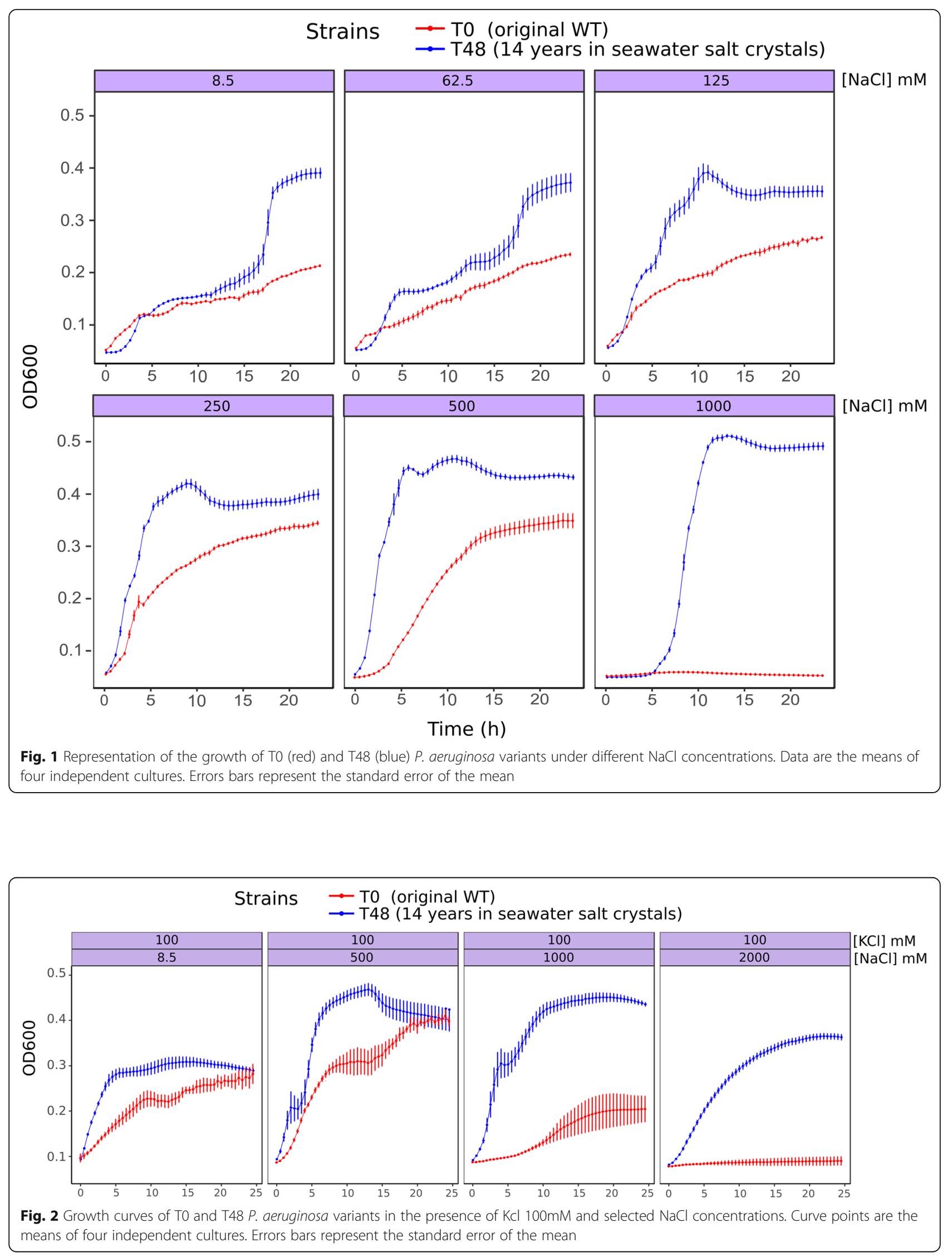
approach based on the Illumina MiSeq platform. Seven non-synonymous substitutions were found in the sequenced clones. These mutations were present in one aromatic amino acid transporter, prepilin-type $\mathrm{N}$-terminal cleavage/methylation domain-containing protein, FHA domain-containing protein, hybrid sensor histidine kinase/response regulator and two hypothetical proteins. In addition, three SNPs resulting in a synonymous substitution (c.795G > C p.Arg265Arg; c.34 T > C p.Leu12Leu and c.54C $>\mathrm{T}$ p.Ser18Ser) respectively in DNA polymerase III subunit beta and in two hypothetical proteins were also detected by WGS (Table S1). Three other mutations were identified in intergenic sites. The products of the genes with non-synonymous mutations do not seem to contribute in salt stress response. Overall, the lack of convergence in the mutations makes difficult to assign any effect to these SNPs. Suggesting that the changes on salt resistance in the studied strain were probably associated with adaptive response based on changes in global gene expression.

\section{Transcriptome profiling of salt-trapped $P$. aeruginosa}

As the phenotype of T48 clones cannot be easily explained by mutations, differences between $\mathrm{T} 0$ and $\mathrm{T} 48$ may be due to physiological changes that remain after the recovery from the seawater salt crystals. To investigate the differential gene expression between the wildtype $\mathrm{T} 0$ and its salt-tolerant derivate $\mathrm{T} 48$, transcriptome analysis by microarrays rendered 78 genes with significant changes in their expression level. From these 78 genes, 25 are genes related to cellular metabolism, 18 are associated to virulence factors, 14 are hypothetical proteins, 11 are associated to transporters and regulatory peptides, 4 are membrane proteins, 4 are implicated in post translational modification and 2 are chaperones and heat shock proteins (Table 2). A global view of all differentially expressed genes is presented in the MA plot in the Additional file 2: Figure S1.

From the 25 genes encoding enzymes or proteins implicated in the cellular metabolism which are differentially expressed between T0 and T48, 20 genes are upregulated and five are down-regulated. When the 18 genes associated with expression of virulence factors are analysed, all Type III Secretion System (T3SS) proteins and two cytotoxin secretion factor exoenzymes, ExoS (PA3841) and ExoT (PA0044) are up-regulated (Table 2). A remarkable increase of the expression of $\mathrm{H}^{+}$transport T3SS ATPase ( $p s c N$ - PA1697) was also observed in T48 strains. Interestingly, its product can be responsible for $\mathrm{Na}^{+}$extrusion in P. aeruginosa. A substantial homeostatic capacity is necessary for adaptation and tolerance to a change in the external environment.

There are eight genes encoding transporters that were up-regulated in T48. Except for the genes related to the symport of $\mathrm{Na}^{+}$/Alanine/Glycine (PA2252), transport of sulphate (cysW-PA0281 and cysT-PA0282), and the C5dicarboxylate transport (PA5530), all transporters are putative components of ABC transporters (PA2204, PA3019), and putative amino acid permeases (PA3641, PA0789). Additionally, three genes (a probable AGCS $\mathrm{Na}^{+}$/alanine/glycine symporter - PA2252, a probable amino acid permease - PA3641, and nqrB - PA2998) involved in $\mathrm{Na}^{+}$ions transport (GO:0006814) were induced in the T48 variants (fold change 3.10, 2.42 and 2.11 respectively; Additional file 1: Table S1 and Additional file 3: Table S2).

There is also a set of genes (14 in total) coding for unknown functions that are differentially regulated, half of them are up-regulated and the rest down-regulated (Table 2). Interestingly, when these results are linked to the genome sequence analysis, none of the differentially regulated hypothetical proteins had mutations in the ORF or the promoter. One of these up-regulated hypothetical proteins is $y j j T$ (PA4627), which product could be a putative rRNA (Guanin-N2)-methyltransferase (GO:0008990) according to the Gene Ontology analysis.

\section{Gene ontology analysis}

A global analysis of the differentially regulated genes by Gene Ontology (GO) was performed. Such analysis revealed that the majority of the proteins are grouped according to the "catalytic activity" and "binding" biological functions (Fig. 3a, Additional file 4: Table S3). When analysed the cellular component category of the GOs, "cell part" which com $P$. aeruginosa prises the "plasma membrane" and "intracellular" categories and "macromolecular complex" represent the two groups (Fig. 3b). Additionally, the regulated genes could be involved in two biological processes: "metabolic process" and "cellular process" (Fig. 3c). When analysed, the product genes' functions, "transferases", "oxidoreductases", "hydrolases", and "lyases" are the most abundant protein functions (Fig. 3d). Stressed bacteria followed a complex adaptive response that involves different biological processes such as the regulation of oxidationreduction process, regulation of cell shape, transmembrane transport systems and cell redox homeostasis.

\section{Salt tolerance assay of $P$. aeruginosa mutants}

The detection of a large number of genes differentially regulated in the T48 variant (Table 2) confirmed the hypothesis that high salt resistance in T48 is linked to many genes that participate together in the adaptive response of $P$. aeruginosa. However, it is difficult to determine the individual contribution of each gene in the adaptation to hypersalinity. For this reason, to investigate the individual contribution of each one of the differentially regulated genes in the T48 variant, we decided to explore their available mutants in the $P$. aeruginosa 
Table 2 Pseudomonas aeruginosa genes differentially regulated between T0 strain and its T48-derivative clones

\begin{tabular}{|c|c|c|c|c|c|}
\hline Functional class ${ }^{\mathrm{a}}$ & Gene $^{a}$ & ProbelD ${ }^{b}$ & Fold change $^{c}$ & Operon $I^{d}$ & $p$ Val \\
\hline \multicolumn{6}{|l|}{ Adaptation/protection } \\
\hline Iron-sulfure cluster assembly transcription factor & isch & PA3815* & 2.00 & ID777 & 0.00097 \\
\hline Bacterioferritin & $b f r B$ & PA3531* & -2.02 & & 0.0028 \\
\hline \multicolumn{6}{|l|}{ Regulation } \\
\hline Probable transcriptional regulator & & PA0547* & 2.08 & ID118 & 0.0033 \\
\hline \multicolumn{6}{|l|}{ Postranslational modification/degradation } \\
\hline DNA-specific endonuclease I & endA & PA2749 & 2.06 & & 0.0088 \\
\hline tRNA (guanine-N(1)-)-methyltransferase & $\operatorname{trmD}$ & PA3743* & 2.22 & ID762 & 0.00042 \\
\hline Ribosomal protein L11 methyltransferase & pmrA & PA4850* & 2.01 & ID996 & 0.0015 \\
\hline Regulator of secondary metabolites/Carbon storage regulator & $r s m A$ & PA0905* & -2.23 & & 0.0036 \\
\hline \multicolumn{6}{|l|}{ Secreted factors } \\
\hline Exoenzyme S & exos & PA3841 & 3.51 & & 0.000064 \\
\hline Exoenzyme T & exoT & PA0044 & 2.74 & & 0.00038 \\
\hline \multicolumn{6}{|l|}{ Protein transport and protein secretion (Type III Secretion System) } \\
\hline Hydrogen ion transportType III secretion system ATPase & & PA1697 & 3.40 & & 0.00011 \\
\hline ExsD & $\operatorname{exs} D$ & PA1714 & 2.51 & & 0.0033 \\
\hline ExsC protein secretion export apparatus & $\operatorname{exs} C$ & PA1710 & 2.92 & & 0.00077 \\
\hline Translocation protein & $\operatorname{psc} P$ & PA1695 & 2.21 & ID359 & 0.0048 \\
\hline Secretion protein & per1 & PA1699 & 2.47 & ID360 & 0.0013 \\
\hline Secretion protein & pcr2 & PA1700 & 2.46 & ID360 & 0.00034 \\
\hline Secretion protein & pcr3 & PA1701* & 2.13 & ID360 & 0.00075 \\
\hline Secretion protein & perV & PA1706* & 3.27 & ID360 & 0.0000051 \\
\hline Regulatory protein & $\mathrm{pcrH}$ & PA1707* & 2.38 & ID360 & 0.00090 \\
\hline Translocation protein & popB & PA1708* & 2.89 & ID360 & 0.00016 \\
\hline Translocation OMP protein & popD & PA1709* & 3.62 & ID360 & 0.000035 \\
\hline Regulatory protein (exoenzyme S synthesis protein B) & $\operatorname{exs} B$ & PA1712* & 2.17 & ID361 & 0.0031 \\
\hline Type III export protein PscD & $\operatorname{psc} D$ & PA1717 & 2.05 & ID362 & 0.018 \\
\hline Export protein & pscF & PA1719 & 2.86 & ID362 & 0.00032 \\
\hline Type III export protein PsCJ & psc & PA1723 & 2.34 & ID362 & 0.0043 \\
\hline Translocation protein & $\mathrm{pscO}$ & PA1696 & 2.18 & & 0.0049 \\
\hline \multicolumn{6}{|l|}{ Transport of small molecules } \\
\hline Sulfate transport protein CysW & cysW & PA0281 & 4.13 & & 0.000016 \\
\hline Probable binding protein component of $A B C$ transporter & & PA2204 & 3.84 & & 0.0000086 \\
\hline $\mathrm{Na}^{+} /$alanine/glycine symporter & & PA2252 & 3.10 & & 0.00029 \\
\hline Probable MFS dicarboxylate transporter & & PA5530* & 2.67 & & 0.00011 \\
\hline Sulfate transport protein CysT & cys $T$ & PA0282 & 2.55 & & 0.0016 \\
\hline Probable amino acid permease & & PA3641 & 2.46 & & 0.0012 \\
\hline Probable amino acid permease & & PA0789 & 2.37 & & 0.0076 \\
\hline Probable ATP-binding component of ABC transporter & & PA3019* & 2.24 & & 0.0030 \\
\hline \multicolumn{6}{|l|}{ Metabolism/enzymes } \\
\hline S-adenosylmethionine decarboxylase proenzyme & speD & PA0654* & 2.66 & & 0.00038 \\
\hline Aspartate ammonia-lyase & aspA & PA5429 & 2.56 & & 0.0029 \\
\hline Sulfite reductase & cysl & PA1838 & 2.47 & & 0.0029 \\
\hline 6-phosphogluconolactonase & pgl & PA3182 & 2.44 & & 0.0018 \\
\hline Soluble pyridine nucleotide transhydrogenase & sth & PA2991 & 2.35 & & 0.0041 \\
\hline Probable ferredoxin & & PA1551* & -2.29 & ID327 & 0.0017 \\
\hline
\end{tabular}


Table 2 Pseudomonas aeruginosa genes differentially regulated between T0 strain and its T48-derivative clones (Continued)

\begin{tabular}{|c|c|c|c|c|c|}
\hline Functional class ${ }^{\mathrm{a}}$ & Gene $^{a}$ & ProbelD ${ }^{b}$ & Fold change $^{c}$ & Operon ID ${ }^{d}$ & $p$ Val \\
\hline Cytochrome C-oxidase, cbb3-type, CcoP subunit & CCOP2 & PA1555* & -2.22 & & 0.0041 \\
\hline Probable cytochrome c oxidase subunit & & $\underline{\text { PA1556* }}$ & -2.02 & ID329 & 0.0029 \\
\hline Probable cytochrome oxidase subunit (cbb3-type) & cCON2 & PA1557* & -2.02 & ID329 & 0.0087 \\
\hline Sulfate adenylyltransferase & $\operatorname{cys} \mathrm{N}$ & PA4442 & 2.12 & & 0.0029 \\
\hline NAD-dependent glutamate dehydrogenase & $g d h B$ & PA3068 & 2.30 & & 0.0025 \\
\hline Glyceraldehyde 3-phosphate dehydrogenase & gapA & PA3195 & 2.08 & & 0.0071 \\
\hline Co-chaperone HscB & $h s c B$ & PA3811 & 2.62 & ID777 & 0.00063 \\
\hline Ferredoxin (2Fe-2S) & $f d x 2$ & PA3809 & 2.40 & ID777 & 0.0016 \\
\hline L-cysteine desulfurase & iscs & PA3814* & 2.07 & ID777 & 0.0020 \\
\hline Geranyltranstransferase & ispA & PA4043* & 2.14 & ID821 & 0.00087 \\
\hline $\mathrm{N}$-acetylglucosaminyl transferase & murG & PA4412 & 2.07 & ID903 & 0.0060 \\
\hline cytochrome o ubiquinol oxidase, subunit I & CyoB & PA1318 & 2.04 & & 0.0062 \\
\hline 2-keto-3-deoxy-6-phosphogluconate aldolase & & PA3181 & 2.02 & & 0.013 \\
\hline Cytochrome o ubiquinol oxidase, subunit III & cyol & PA1319 & 2.01 & & 0.010 \\
\hline Sulfate adenylyltransferase subunit 2 & cys $D$ & PA4443* & 2.66 & ID908 & 0.00026 \\
\hline Cell division protein FtsJ & fts」 & PA4752* & -2.00 & & \\
\hline Probable beta-ketoacyl synthase & & PA5174 & 2.19 & & 0.00047 \\
\hline $\mathrm{Na}^{+}$-transporting NADH:ubiquinone oxidoreductase, subunit $\mathrm{NqrB}$ & nqrB & PA2998 & 2.11 & & 0.0065 \\
\hline Ribosomal RNA small subunit methyltransferase $C$ & rsmC & PA4627* & 2.39 & & 0.0025 \\
\hline \multicolumn{6}{|l|}{ Chaperonnes \& heat shock proteins } \\
\hline Molecular chaperone Dnak & $\underline{\text { dnaK }}$ & $\underline{\text { PA4761* }}$ & -2.16 & ID978 & 0.0076 \\
\hline ATP-dependent protease ATP-binding subunit & $\underline{h s l U}$ & PA5054* & -2.02 & & 0.0080 \\
\hline \multicolumn{6}{|l|}{ Membran proteins and LPS } \\
\hline Heptosyltransferase II & waaF & PA5012 & 2.04 & & 0.0096 \\
\hline RodA rod shape-determining protein & $\operatorname{rod} A$ & PA4002 & 2.04 & & 0.011 \\
\hline Outer membrane protein OprG precursor & oprG & PA4067* & -2.02 & & 0.0057 \\
\hline $\mathrm{Na}^{+} / \mathrm{H}^{+}$ion antiporter subunit & shaD & $\underline{\text { PA1057* }}$ & 2.01 & ID228 & 0.0092 \\
\hline \multicolumn{6}{|l|}{ Unknown fonction } \\
\hline Hypothetical protein & & PA0284 & 2.23 & & 0.0019 \\
\hline Hypothetical protein & & PA0310* & -2.02 & & 0.0083 \\
\hline Hypothetical protein & & PA0570 & 2.12 & ID123 & 0.0011 \\
\hline Hypothetical protein & & PA0915* & 2.32 & ID197 & 0.0013 \\
\hline Hypothetical protein (predicted transmembrane protein) & & PA1209* & -3.35 & & 0.00020 \\
\hline Hypothetical protein (type II lipoprotein export signal predicted) & & PA1228 & 2.35 & & 0.0015 \\
\hline Hypothetical protein (predicted transmembrane protein) & & PA2501* & -2.64 & & 0.0011 \\
\hline Hypothetical protein (NnrS-like membrane protein) & & PA2662* & 2.13 & ID556 & 0.00048 \\
\hline Hypothetical protein (predicted transmembrane protein) & & PA2757* & 2.01 & & 0.0045 \\
\hline Hypothetical protein & & PA3572 & -2.23 & & 0.00065 \\
\hline Hypothetical protein (type I lipoprotein export signal predicted) & & PA4390* & 2.16 & & 0.0028 \\
\hline Hypothetical protein (predicted transmembrane protein) & & PA4517* & -2.42 & & 0.00044 \\
\hline Hypothetical protein & & PA4611* & -2.22 & & 0.0073 \\
\hline Hypothetical protein & & PA5446* & -3.18 & & 0.00014 \\
\hline
\end{tabular}

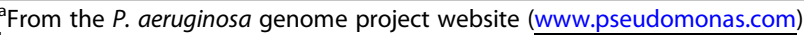

${ }^{\mathrm{b}}$ Probe ORFs identifier for $P$. aeruginosa PAO1

${ }^{\mathrm{C}}$ Fold regulation of $P$. aeruginosa genes differentially expressed between $\mathrm{TO}$ and $\mathrm{T} 14 \mathrm{Y}$ variants

${ }^{\mathrm{d} C}$ Computationally predicted operons from the Database of the prokaryotic operons

Asterisks indicate the genes inactivated in the 39 mutants tested for changes in growth in high $\mathrm{NaCl}$ concentrations

Underlined genes are those whose inactivation increases growth in high $\mathrm{NaCl}$ concentrations 


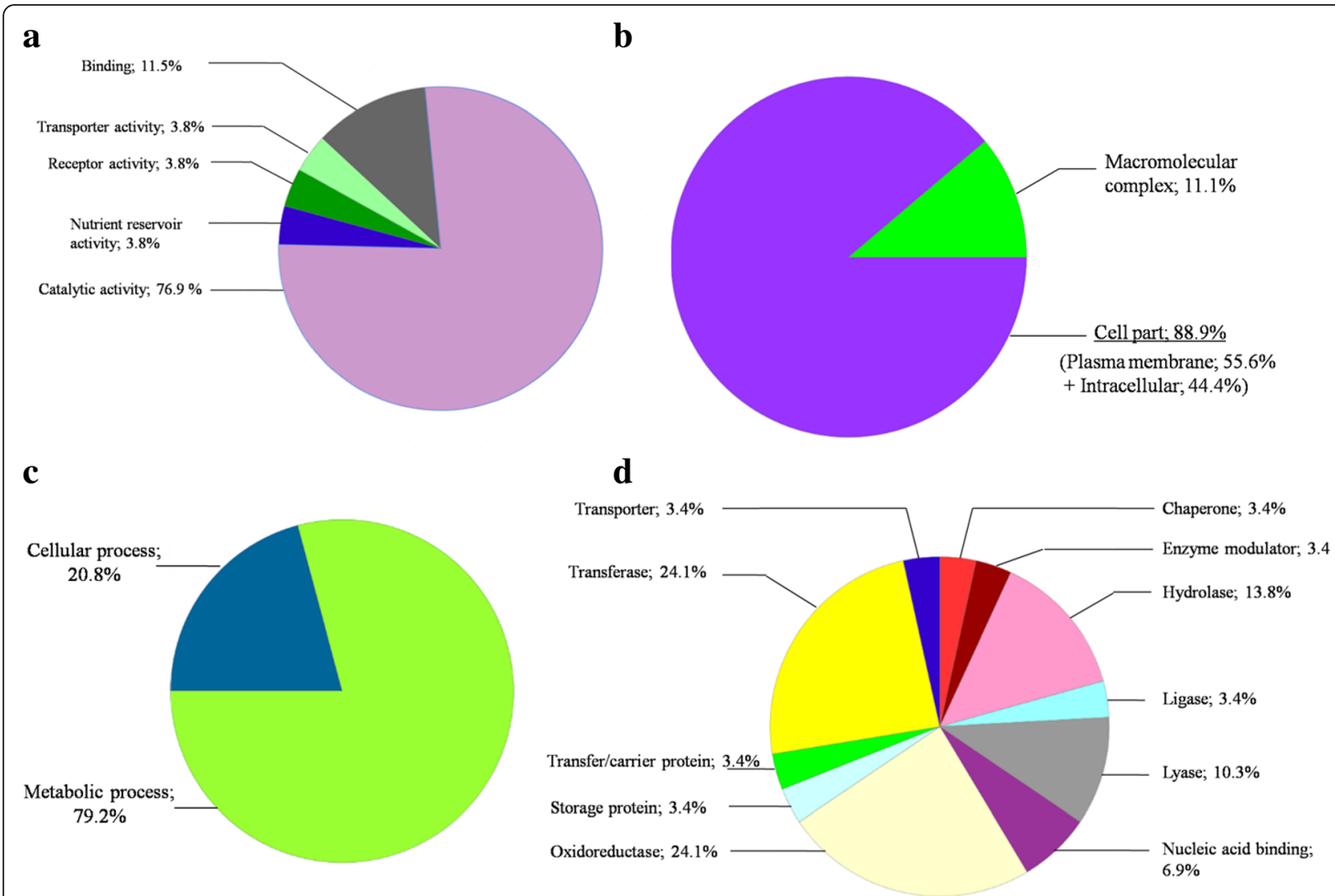

Fig. 3 Functional characterisation of the altered genes in P. aeruginosa T48 using gene ontology analysis. a: molecular function classification; b: cellular component classification; $\mathbf{c}$ : biological process classification; $\mathbf{d}$ : PANTHER protein class of gene products

PA14 transposon insertion library [14]. From 78 differentially regulated genes, mutants for 39 genes could be recovered from the library (Additional file 3: Table S2). These individual knock-out mutants were tested for growth at different $\mathrm{NaCl}$ concentrations. Our results indicated that only mutants in $c \mathrm{coO} 2$ (cytochrome $c$ oxidase subunit), PA4517 (conserved hypothetical protein), dnaK (chaperone), and hslU (ATP-dependent protease) showed a significant difference with the wild type when grown in 8.5 and $500 \mathrm{mM} \mathrm{NaCl}$ (Fig. 4). Some mutants (in PA1556, PA4517 and PA4761) grew worse than the parental strain in low salt concentration $(8.5 \mathrm{mM} \mathrm{NaCl})$, while all they did grow better in high salinity medium (500 mM).

\section{Discussion}

The results of this study show that $P$. aeruginosa can survive and adapt to prolonged extreme stress conditions. The obtained data suggest that the differential response to salt stress between $\mathrm{T} 0$ and $\mathrm{T} 48$ variants is not linked to specific mutational events. This in line with previous finding with these clones recovered from salt, where there has been shown that after several passages, bacteria recover their normal phenotype [15]. However, we cannot discard that some of the detected mutations could play a role in the observed phenotypes. Genetic manipulation of $P$. aeruginosa at single nucleotide level is nowadays still a challenge.

The gene expression analysis revealed that many genes are differentially regulated in the stressed cells. The differential induction of membrane transporters may reflect altered ion fluxes between the bacterial cell and the surrounding medium to maintain homoeostasis. In fact, the primary response of bacteria to a highly osmotic environment is the accumulation of certain solutes, like $\mathrm{K}^{+}$, glutamate, trehalose, proline, and glycine betaine, at concentrations that are proportional to the osmolarity of the medium [16].

When bacteria face a growing concentration of $\mathrm{Na}^{+}$, they actively transport $\mathrm{K}^{+}$ions [16]. A recent study demonstrated that a steady $\mathrm{K}^{+}$supply, even under unfavourable energetic conditions, plays a key role in long-term survival and desiccation tolerance for Halobacteriumsalinarum within salt crystal [17]. This is consistent with the fact that $\mathrm{Na}^{+} / \mathrm{K}^{+}$transporters were slightly induced in the T48 variant, including, the glutathione-regulated $\mathrm{K}^{+}$-efflux system protein KefB (PA1207; 1.5-fold regulation) and a putative $\mathrm{K}^{+}$channel (PA1496; 1.52-fold 


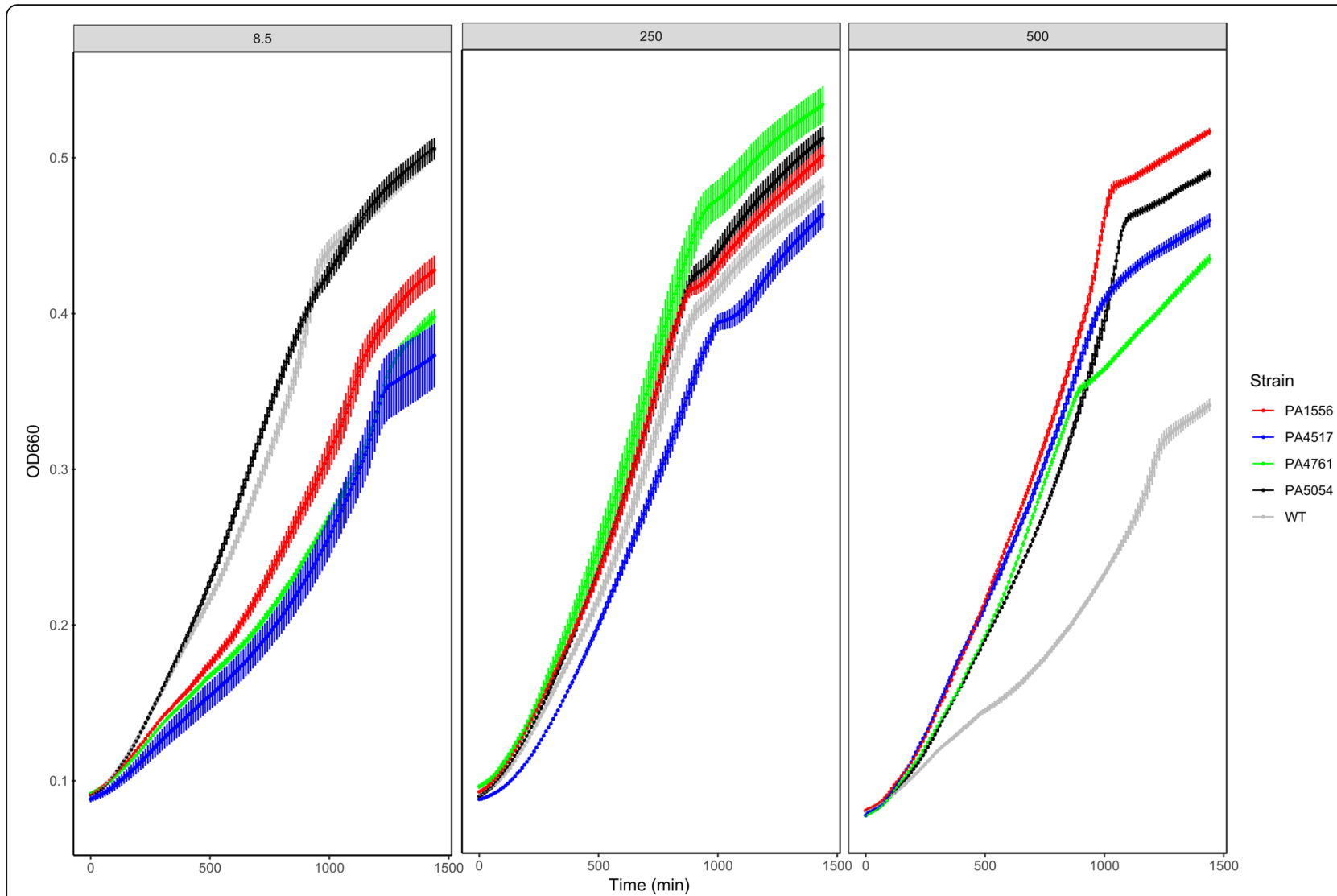

Fig. 4 Salt tolerance assay of P. aeruginosa PA14 mutant collection that showed differential expression in the microarray experiment. Curve points are the mean growth of four independent cultures. Errors bars represent the standard error of the mean

regulation). $\mathrm{K}^{+}$transporters are regulated by an increase in environment osmolarity regardless of the solute used and turgor. This response is modulated by the external concentrations of $\mathrm{Na}^{+}$. The $\mathrm{K}^{+}$ions act as a cytoplasmicsignaling molecule, activating and/or inducing enzymes and transport systems that allow the cell to adapt to elevated salinity $[12,16]$.

Additionally, three genes involved in $\mathrm{Na}^{+}$ion transport (GO:0006814) were induced in the T48 variants (PA2252, PA3641 nqrB - PA2998; fold change 3.10, 2.42 and 2.11 respectively; Tables $\mathrm{S} 1$ and $\mathrm{S} 2$ ). The product of $n q r B$ gene is a unique energy-transducing complex, widely distributed among marine and pathogenic bacteria. It converts the energy from the oxidation of NADH and the reduction of quinone into an electrochemical $\mathrm{Na}^{+}$-gradient that can provide energy to the cell [18]. In addition, it allows the $\mathrm{Na}^{+}$ion to pass through the hydrophobic core of the membrane and provides cation specificity to the translocation system [19]. These results are complementary with the 6 up-regulated and 13 down-regulated transporters (Table 2). From these 6 up-regulated transporters, $r n f C$ (PA3491) is related with the electron transport complex, which is overexpressed when IscR is up-regulated [20]. In contrast, rnfE (PA3494), the putative periplasmic component of the RNF system [21], is underexpressed in T48 variants, a contradiction as the RNF system is very close to the $\mathrm{Na}^{+}$-pumping NADH:ubiquinone oxidoreductase $[14,21]$. Another important up-regulated transporter is $c z c B$ (PA2521), which is associated with resistance to heavy metals [22-24], but recently it was discovered that it is also responsible for $\mathrm{Ca}^{2+}$ ions homeostasis [25]. Other up-regulated transporters are narK1 (PA3877; related with the nitrate respiration under anaerobic conditions $[25$, 26]), ompI (PA3894; related to the aminoglycoside resistance [27]), and two more probable transporters with unknown associated metabolites (PA1876, yhiH - PA5231). Despite the fact that the gene coding for OmpI is upregulated in T48 (Table 2), MexCD (PA4598 and PA4599) transporters, which are related to fluoroquinolones resistance [81, 82], are down-regulated. Similarly, LptG (PA3827), a lipopolysaccharide export system permease, is also down-regulated. Regarding transporters related to carbohydrate transport, RbsA (PA1947) and YhhS (PA1993) are also down-regulated. Finally, the rest of the down-regulated transporters are putative MFS and ABC type transporters of unknown metabolites, except for a putative $\mathrm{K}^{+}$channel (PA1496) and YdfC (PA2777), a putative formic/nitrite transporter 
which was also found to be expressed under antibiotic stress [28, 29].

Four members of the 8-gene operon iscR-PA3808 the ferredoxin Fdx2 (PA3809), the co-chaperone HscB (PA3811), the L-cysteine desulfuraseIscS (PA3814), and the iron-sulphur cluster assembly transcription factor IscR (PA3815) are up-regulated, supporting previous observations about their expression in high concentration of salts [20]. Surprisingly, we did not find any significant upregulation of the IscR-regulated ferredoxin FprB (PA4615), which are also associated with salt stress [30]. Other up-regulated genes are implicated in posttranslational modifications such as trmD (PA3743; tRNA guanosine methyltransferase) and endA (PA2749; DNAspecific endonuclease I). Methylation of coding or noncoding RNA might play an important role in gene expression regulation [31]. Moreover, the S-adenosylmethionine decarboxylase proenzyme (speD; PA0654), involved in spermidine biosynthesis, was up-regulated in the T48 variants. Interestingly, previous works reported that spermidine is effective in alleviating the adverse effect of salt stress on plants [32,33]. A recent finding indicated that spermidine priming treatments enhanced the antioxidant systems in plants exposed to salt stress and contributed to improved ion homeostasis [32-34]. Similarly, in P. aeruginosa, Johnson et al [34] reported that spermidine plays an important function as an organic polycation to bind lipopolysaccharide and to stabilize the cell surface. It protects the outer membrane from aminoglycoside antibiotics, antimicrobial peptides, and oxidative stress.

Another up-regulated gene coding for a two-component system response regulator PmrA (PA4776), was identified in this study, which was recently reported to be associated with polymyxin resistance and hence osmotic stress [35].

The rsmA gene, known to be a regulator of the secondary metabolism and a carbon storage regulator, is down-regulated in salt-tolerant clones (Table 2). RsmA was found to play a very important role in early pathogenesis, especially in early colonisation and dissemination [36], due to its relevance in the expression of Type VI Secretory System (T6SS) [37, 38]. Moreover, rsmAknockouts strains of $P$. aeruginosa have altered the expression of genes involved in a wide variety of pathways, including iron acquisition, formation of multidrug efflux pumps and motility [39]. The genes coding for TssK1 (PA0079) and IcmF2 (PA1669) are also down-regulated. Both proteins are fundamental for the pathogenesis of $P$. aeruginosa, as the former is implied in the assembly of T6SS complex [40] while the latter is involved in the virulence [41].

Most of these T3SS proteins are members of the 12gene operon popN-popD, which are expressed not only in pathogenesis but also under different environmental stresses such as low concentration of $\mathrm{Ca}^{2+}$ or direct contact with host cells [42]. Additionally, ExoS and ExoT have an ADP-ribosyltransferase activity, playing an important role in the bacterial survival and dissemination in clinical strains [43-45].

Salt stress also showed impact on three metabolic genes that were up-regulated: the cytochrome $c$ oxidase ( $\operatorname{cox} A$; PA0106), a putative acyl-CoA dehydrogenase (PA0508), and the anthranilate-coenzyme A ligase (pqsA; PA0996). Previously, the putative acyl-CoA dehydrogenase, a gene associated with changes in membrane fluidity [46], was found overexpressed in Burkholderia pseudomallei when treated with $\mathrm{NaCl}$. The fact that pqsA is up-regulated may indicate that the Pseudomonas quinolone signal (PQS) could be also overexpressed during salt encapsulation. This protein shapes bacterial population structure to survive under stressful environments and kills sensitive bacteria at a time that promotes antioxidative stress response [47].

When transcriptional regulators are analysed, only a putative transcriptional regulator (PA0547) is upregulated in T48, having a potential role in the differential regulation of gene expression. However, hslU (PA5054) and dnaK (PA4761) genes, which encode for chaperone activity are found significantly downregulated. This observation is in contrast with previous studies, where $d n a K$ was overexpressed, being relevant in salt resistance in Lactococcuslactis [48]. Moreover, $d n a K$ was also found up-regulated in marine bacteria allowing the adaptation to cold environments [49]. Possibly, these chaperones were up-regulated in salt-trapped bacteria but, once the T48 variant was recovered, these genes are quickly down-regulated due to other salt stress adaptations, the same maybe true for other genes.

CgrA (PA2127), which is found to be related to the expression of RsmN and, thus, the repression of RsmA [38], is up-regulated in T48 variant. The $\operatorname{cgr} A$ gene plays a key role in the expression of fimbrial genes and is related to MvaT mutants or anaerobic growth [50]. Despite the fact that only narK1 (PA3877) was found to be up-regulated, results indicate that most of the upregulated genes in T48 are associated to aerobic growth. Additionally, no mutations in the MvaT transcriptional regulator were revealed by whole genome analysis.

According to our results, salt resistance could be considered as a priming response, i.e. as a physiological process by which organisms prepare themselves for more quick or aggressive situations to future biotic or abiotic stress [51]. Although this phenomenon has been studied mostly in plants, there are also some examples of priming in the bacterial world. One critical issue is to explore how the signals that induce priming are received and transduced by the cells and prepare the bacteria for long-term persistence if growth is not possible. In plants, priming to salinity plays an important role as adaptive 
phenotypic strategy [52]. This process could develop different defence mechanisms in the cells against salinity stress such as antioxidant defence systems, the repair of membranes and the osmotic adjustment [53]. This kind of response is characterised, essentially, by the slow induction of many genes that together contribute to the acquisition of quick and effective adaptive strategy against stressor conditions. In such cases, molecular mechanisms responsible for priming effects are involved in the accumulation of signalling proteins or transcription factors [54], as well as epigenetic mechanisms [55, 56]. These epigenetic mechanisms are thought to bring a faster and more potent response to subsequent exposure to stress. This idea is supported for the Gene Ontology analysis, which suggested that some genes were involved in regulation of transcription, methylation process, response to stimulus, RNA metabolic processes and quorum sensing.

Interestingly, neither the mutants nor the wild-type were able to grow in $\mathrm{DM}$ with $1 \mathrm{M} \mathrm{NaCl}$. All these genes showed a decreased transcription in the T48 variant and, consequently, if they are involved in adaptation to hypersalinity, a better growth under high $\mathrm{NaCl}$ concentration is expected when inactivated. Moreover, no sequence changes between the five genes from $\mathrm{T} 0$ and $\mathrm{T} 48$ were found, suggesting that the differences in growth under high salt conditions may be due to differential regulation, which requires further research to be clarified. The preservation of a long-lasting phenotype is not new in bacteria. For instance, the lactose metabolization response in Escherichia coli is maintained during more than ten generations after the removal of lactose due to the inheritance of very stable proteins [57].

\section{Conclusions}

Pseudomonas aeruginosa can survive in inclusions of seawater crystals for many years. Upon recovery, this bacterium shows a better ability to grow in highly saline conditions, and the adaptation seems to be only phenotypic but not genetic, indicating a 'priming' phenomenon in this plastic bacterium. Although we have identified several genes potentially involved in adaptation to saline environments, the exact mechanisms which are responsible for priming in P. aeruginosa remain unclear. Our study provides a good start toward a deep understanding of the long-term salt stress behaviour of $P$. aeruginosa.

\section{Methods}

\section{Bacterial model and growth conditions}

P. aeruginosa ATCC 27853 (wild-type: T0 in this study) was grown overnight at $37^{\circ} \mathrm{C}$ in nutrient broth, centrifuged at 13,000 rpm for $10 \mathrm{~min}$, washed three times and then suspended in filter-sterilised seawater to a final concentration of approximately $10^{9} \mathrm{CFU} / \mathrm{ml}$ in three independent replicas. Cells were incubated during 14 years in closed Erlenmeyer flasks at room temperature. The concentration of salts in the used seawater was 37 $\mathrm{g} / \mathrm{l}$. The water was allowed to evaporate, the saline crystals were apparent after 8 months, and the culture became completely desiccated after 10 months. The initial number of $\mathrm{CFU} / \mathrm{ml}$ was confirmed by serial decimal dilutions in nutrient agar.

\section{Revitalisation of the bacterial cells}

$P$. aeruginosa cells, maintained during 14 years in sterilised seawater, were revitalised by the addition of $100 \mathrm{ml}$ of sterilised nutrient broth to the salt crystal in the Erlenmeyer flask and incubated at $37^{\circ} \mathrm{C}$ with $100 \mathrm{rpm}$ of shaking. Subsequent plating of an aliquot from this culture on nutrient agar yielded observable colonies. A few isolated colonies from the different replicas were recovered and saved for further analysis. Biochemical profiles of $P$. aeruginosa ATCC 27853 and the resuscitated cells (T48 variant in this study) were characterised using API 20NE system (bio-Merieux, France).

\section{Evaluation of fitness in different salinity conditions}

Bacterial growth curves were carried out in flatbottomed 96-well microplates (Nunc, Denmark). Each well was filled with $100 \mu \mathrm{l}$ of Davis Minimal medium (DM: Na2HPO4 $6.78 \mathrm{~g} / \mathrm{l} ; \mathrm{KH} 2 \mathrm{PO} 43 \mathrm{~g} / \mathrm{l} ; \mathrm{NaCl} 0.5 \mathrm{~g} / \mathrm{l}$; $\mathrm{NH} 4 \mathrm{Cl} 1 \mathrm{~g} / \mathrm{l} ; 1 \mathrm{mM} \mathrm{MgSO} 4 ; 0.1 \mathrm{mM} \mathrm{CaCl} 2,0.28 \%$ Glucose and $0.25 \%$ casamino acids), supplemented with $\mathrm{NaCl}$ to final concentrations of $2 \mathrm{M}, 1 \mathrm{M}, 500 \mathrm{mM}, 250$ $\mathrm{mM}$ and $8.5 \mathrm{mM}$. Overnight cultures of T0 and T48 $P$. aeruginosa cells were added to a final OD595 of 0.04 . The growth of T0 and T48 variants was followed with four replicas of each one in the same concentrations of $\mathrm{NaCl}$. Microplates were incubated in an Infinite F200 TECAN microplate reader for $24 \mathrm{~h}$ at $37^{\circ} \mathrm{C}$ with $15 \mathrm{~s}$ of shaking duration, $3 \mathrm{~mm}$ of shaking amplitude. The interval time of absorbance measurements at $595 \mathrm{~nm}$ was 15 min. The same manipulation was repeated adding 100 $\mathrm{mM} \mathrm{KCl}$ to selected concentrations of $\mathrm{NaCl}$.

\section{Whole genome sequencing after recovery from salt}

Libraries were prepared using a TruSeq DNA PCR-Free Library Preparation Kit (Illumina, USA) and were sequenced on an Illumina-MiSeq system using a 600-cycle v3 reagent kit, resulting in 300-bp paired-end reads. Sequence data are available from the NCBI database under Bioproject accession PRJNA420955. A reference genome for strain $P$. aeruginosa ATCC 27853 was assembled using A5-miseq version 20,140,604 and annotated using prokka version 1.12-beta [58]. Snippy version 3.2 [59] was used to identify variants in strains $\mathrm{c} 1-5$ (clone1 to clone5) relative to the reference complete genome of $P$. aeruginosa ATCC 
27853 (Genbank accession CP015117). Assembly of 1,818, 724 error-corrected reads (estimated 47.68-fold coverage) resulted in 46 contigs with an N50 of $353 \mathrm{~kb}$ and a total size of $6.79 \mathrm{Mb}$.

\section{Transcriptome profiling of salt-trapped $P$. aeruginosa}

To find out what genes are involved in the differential salinity resistance, global transcription profile of cultures of $P$. aeruginosa T0 and its T48-derivative variant were carried out using microarray technology. Bacterial cells were grown overnight in Davis Minimal medium (DM) at $37^{\circ} \mathrm{C}$ under $200 \mathrm{rpm}$ of shaking. Three independent $1 / 50$ dilutions of each of them were grown until they reached an optical density of 0.5 at $600 \mathrm{~nm}$. The cells were washed and resuspended in DM supplemented with RNA Protect reagent (Qiagen, Germany). Cell lysis and total RNA extractions were performed with the RNeasy mini kit according to the manufacturer's recommendations (Qiagen, Chatsworth, CA), except that 1 $\mathrm{mg} / \mathrm{ml}$ of lysozyme was used to lyse Pseudomonas cells. DNase digestions were carried out on the column by adding 82 units of Kunitz enzyme (Qiagen) with incubation at room temperature for $15 \mathrm{~min}$. An additional DNase digestion was performed on the purified RNA to ensure the absence of DNA. RNA quality was checked through agarose electrophoresis before cDNA synthesis. Fluorescently labelled cDNA for microarray hybridisation was obtained by using the SuperScript Indirect cDNA Labelling System (Invitrogen) as recommended by the supplier. Briefly, $20 \mu \mathrm{g}$ of total RNA was transformed to cDNA with Superscript III reverse transcriptase using random hexamers as primers and including aminoalyl-modified nucleotides in the reaction mixture. After cDNA purification, Cy3 or Cy5 fluorescent dye (Amersham Biosciences) was coupled to the aminomodified first-strand cDNA. The labelling efficiency was assessed by using a NanoDrop ND1000 spectrophotometer (NanoDrop Technologies). Equal amounts of Cy3or Cy5-labelled cDNAs, one of them corresponding to the control and the other to the problem under analysis, were mixed and dried in a Speed-Vac. Labelled cDNA was hybridised to $P$. aeruginosa microarray slides version 2 from the Pathogen Functional Genomics Resource Center from J. Craig Venter Institute Microbial Hybridization of Labelled Probes protocol. Following hybridization, the slides were washed, dried, and scanned using a ScanArray Express scanner and software (Packard BioScienceBioChip Technologies). For the analysis of DNA microarray slides, background correction and normalization of expression data were performed using LIMMA [60]. To avoid the exaggerated variability of log ratios for low-intensity spots during local background correction, we used the normexp method in LIMMA to adjust the local median background estimates. The resulting log ratios were print-tip LOESS normalised for each array [61]. Only genes that exhibited changes compared to the wild-type control of two-fold and more, as well as $P$ values of $\leq 0.05$, were considered in the study. Finally, to explore the functional roles of the regulated genes, the Gene Ontology (GO) analysis was performed through the PANTHER online software [62] and QuickGO tool [63].

\section{Salt tolerance assay of $P$. aeruginosa mutants}

The desired mutants were isolated from PA14 transposon insertion mutants [64]. The selected $P$. aeruginosa PA14 mutants, with deletions in genes showing transcriptional variation in the microarray experiments, were used. Salt tolerance of these mutants was measured and compared to the wild-type strain PA14. The salt tolerance assay was performed on 96-well polystyrene plates. Each well was filled with $100 \mu \mathrm{l}$ of DM minimal medium supplemented with $\mathrm{NaCl}$ to final concentrations of $8.5 \mathrm{mM}$ (DM with no $\mathrm{NaCl}$ added), $250 \mathrm{mM}$ and $500 \mathrm{mM}$, with four replicas for each $\mathrm{NaCl}$ concentration. The microplates were incubated at $37^{\circ} \mathrm{C}$, and the optical density at $600 \mathrm{~nm}$ was measured after $24 \mathrm{~h}$. For mutants showing statistically significant differences in growth respect the wild-type strain on $\mathrm{NaCl}$ $(>25 \%)$, salt tolerance assay was repeated for each sodium chloride concentration.

\section{Statistical analysis}

All parameters for the growth curves were estimated using Growthcurver [65]. Using this data, all model parameters -carrying capacity, initial population size, growth rate, doubling time and the empirical area under the curvefor all growth curves of both variants, T0 and T48, were compared using Student's $t$ test according to the different $\mathrm{NaCl}$ and $\mathrm{KCl}$ concentrations. Additionally, two-sided Kolmogorov-Smirnov tests were applied to compare the growth curves per treatments. $P$ values less than or equal to 0.05 were considered statistically significant. All statistical tests were performed in R v. 3.4.4 [66].

\section{Additional files}

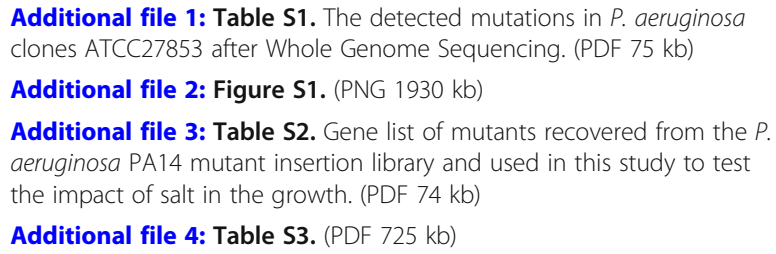

Additional file 3: Table S2. Gene list of mutants recovered from the $P$. aeruginosa PA14 mutant insertion library and used in this study to test the impact of salt in the growth. (PDF $74 \mathrm{~kb}$ )

Additional file 4: Table S3. (PDF $725 \mathrm{~kb}$ )

\section{Acknowledgements}

We are grateful to Prof. Jens Rolff for support and helpful comments from Yeliz Karatas, Arpita Nath from Freie Universität Berlin and Dr. Paul Smith. 


\section{Authors' contributions}

$\mathrm{EH}, \mathrm{EGT}, \mathrm{ClQ}, \mathrm{AB}, \mathrm{KG}$ and $\mathrm{ARR}$ carried out the experimental work. ARR and JB designed the experimental work. PJ contributed with genome sequencing and analysis. All authors conducted analytical work. EH and ARR drafted the manuscript with input from all authors. All authors read and approved the final manuscript.

\section{Funding}

This work was supported by Plan Nacional de I+D+i 2013-2016 and the Instituto de Salud Carlos III, Subdireccion General de Redes y Centros de Investigacion Cooperativa, Ministerio de Economia, Industria y Competitividad, Spanish Network for Research in Infectious Diseases (REIPI RD16/0016/ 0009) — co-financed by the European Development Regional Fund "A Way to Achieve Europe"-by Operative Program Intelligent Growth 2014-2020. ARR was also supported SFB 973 (Deutsche Forschungsgemeinschaft, project C5). We acknowledge support by the German Research Foundation and the OpenAccess Publication Fund of Freie Universität Berlin.

\section{Availability of data and materials}

All data are available in the manuscript and supplementary material. The sequences and genomic data were deposited as indicated in the manuscript.

\section{Ethics approval and consent to participate}

Not applicable.

\section{Consent for publication}

Not applicable.

\section{Competing interests}

The authors declare that they have no competing interests.

\section{Author details}

'Laboratory of Contagious Diseases and Biologically Active Substances LR99-ES27 Faculty of Pharmacy of Monastir, University of Monastir, Monastir, Tunisia. ${ }^{2}$ Department of Microbial Biotechnology, Spanish National Center for Biotechnology (CNB), Madrid, Spain. ${ }^{3}$ Department of Veterinary and Animal Sciences, Center for non-coding RNA in Technology and Health, University of Copenhagen, Copenhagen, Denmark. ${ }^{4}$ Centro de Micro-Bioinnovación, Escuela de Nutrición y Dietética, Facultad de Farmacia, Universidad de Valparaíso, Valparaíso, Chile. ${ }^{5}$ Laboratory of Analysis, Treatment and Valorization of Environmental Polluants and products, Faculty of Pharmacy, University of Monastir, Monastir, Tunisia. ${ }^{6}$ Institute of Biology, FreieUniversität Berlin, Berlin, Germany.

Received: 26 October 2018 Accepted: 31 May 2019

Published online: 24 June 2019

\section{References}

1. Hengge-Aronis R. The general stress response in Escherichia coli. In: Hengge-Aronis GS and R, editor. Bacterial stress responses. Washington, D. C.: ASM Press; i 2000. p. 161-178.

2. Lowenstein TK, Schubert BA, Timofeeff MN. Microbial communities in fluid inclusions and long-term survival in halite. GSA Today. 2011;21:4-9. https:// doi.org/10.1130/GSATG81A.1.

3. McGenity TJ, Gemmell RT, Grant WD, Stan-Lotter H. Origins of halophilic microorganisms in ancient salt deposits. Minireview. Environ Microbiol. 2000;2:243-50. https://doi.org/10.1046/j.1462-2920.2000.00105.x.

4. Norton CF, Grant WD. Survival of Halobacteria within fluid inclusions in salt crystals. J Gen Microbiol. 1988:134:1365-1.

5. Adamski JC, Roberts JA, Goldstein RH. Entrapment of Bacteria in fluid inclusions in laboratory-grown halite. Astrobiology. 2006;6:552-62. https:// doi.org/10.1089/ast.2006.6.552.

6. Fendrihan S, Legat A, Pfaffenhuemer M, Gruber C, Weidler G, Gerbl F, et al. Extremely halophilic archaea and the issue of long-term microbial survival. Re/views Environ Sci bio/technology. 2006;5:203-18. https://doi.org/10.1007/ s11157-006-0007-y.

7. Schubert BA, Lowenstein TK, Timofeeff MN, Parker MA. Halophilic Archaea cultured from ancient halite, Death Valley, California. Environ Microbiol. 2010;12:440-54. https://doi.org/10.1111/j.1462-2920.2009.02086.x.

8. Stover CK, Pham XQ, Erwin AL, Mizoguchi SD, Warrener P, Hickey MJ, et al. Complete genome sequence of Pseudomonas aeruginosa PAO1, an opportunistic pathogen. Nature. 2000;406:959-64. https://doi.org/10.1038/ 35023079.

9. Rodrigue A, Quentin Y, Lazdunski A, Méjean V, Foglino M. Cell signalling by oligosaccharides. Two-component systems in Pseudomonas aeruginosa: why so many? Trends Microbiol. 2000;8:498-504.

10. Langton Hewer SC, Smyth AR. Antibiotic strategies for eradicating Pseudomonas aeruginosa in people with cystic fibrosis. Cochrane Database Syst Rev. 2017;(4):CD004197.

11. Snitkin ES, Segre JA. Pseudomonas aeruginosa adaptation to human hosts. Nat Genet. 2015;47:2-3. https://doi.org/10.1038/ng.3172.

12. Epstein $W$. The roles and regulation of potassium in bacteria. Prog Nucleic Acid Res Mol Biol 2003;75:293-320. http://www.ncbi.nlm.nih.gov/pubmed/ 14604015. Accessed 4 May 2018.

13. Aspedon A, Palmer K, Whiteley M. Microarray analysis of the osmotic stress response in Pseudomonas aeruginosa. J Bacteriol 2006;188:2721-2725. doi: 188/7/2721 [pii] 10.1128/JB.188.7.2721-2725.2006.

14. Reyes-Prieto A, Barquera B, Juárez O. Origin and evolution of the sodium -pumping NADH: ubiquinone oxidoreductase. PLoS One. 2014;9:e96696.

15. Elabed H, Bakhrouf A, Hamza R, Azaiez M, Gaddour K. Evidence of the adaptive response in Pseudomonas aeruginosa to 14 years of incubation in seawater. Ann Microbiol. 2012;62:1385-94.

16. Csonka LN. Physiological and genetic responses of bacteria to osmotic stress. Microbiol Rev 1989;53:121-147. http://www.ncbi.nlm.nih.gov/ pubmed/2651863. Accessed 4 May 2018.

17. Kixmüller D, Greie J-C. An ATP-driven potassium pump promotes long-term survival of Halobacterium salinarum within salt crystals. Environ Microbiol Rep. 2012;4:234-41. https://doi.org/10.1111/j.1758-2229.2012.00326.x.

18. Juárez $\mathrm{O}$, Barquera B. Insights into the mechanism of electron transfer and sodium translocation of the $\mathrm{Na}(+)$-pumping NADH:quinone oxidoreductase. Biochim Biophys Acta. 2012;1817:1823-32. https://doi.org/10.1016/j.bbabio.2012.03.017.

19. Juárez $\mathrm{O}$, Athearn $\mathrm{K}$, Gillespie $\mathrm{P}$, Barquera $\mathrm{B}$. Acid residues in the transmembrane helices of the $\mathrm{Na}+-$ pumping $\mathrm{NADH}$ :quinone oxidoreductase from Vibrio cholerae involved in sodium translocation. Biochemistry. 2009:48:9516-24. https://doi.org/10.1021/bi900845y.

20. Romsang A, Duang-Nkern J, Wirathorn W, Vattanaviboon P, Mongkolsuk S Pseudomonas aeruginosa IscR-regulated ferredoxin NADP(+) reductase gene (fprB) functions in Iron-sulfur cluster biogenesis and multiple stress response. PLoS One. 2015:10:e0134374.

21. Hreha TN, Mezic KG, Herce HD, Duffy EB, Bourges A, Pryshchep S, et al. Complete topology of the RNF complex from Vibrio cholerae. Biochemistry. 2015;54:2443-55.

22. Li K, Pidatala RR, Ramakrishna W. Mutational, proteomic and metabolomic analysis of a plant growth promoting copper-resistant Pseudomonas spp. FEMS Microbiol Lett. 2012;335:140-8.

23. Jain S, Bhatt A. Molecular and in situ characterization of cadmium-resistant diversified extremophilic strains of Pseudomonas for their bioremediation potential. 3 Biotech. 2014;4:297-304.

24. Chong TM, Yin W-F, Chen J-W, Mondy S, Grandclément C, Faure D, et al. Comprehensive genomic and phenotypic metal resistance profile of Pseudomonas putida strain S13.1.2 isolated from a vineyard soil. AMB Express. 2016;6:95

25. Khanam S, Guragain M, Lenaburg DL, Kubat R, Patrauchan MA. Calcium induces tobramycin resistance in Pseudomonas aeruginosa by regulating RND efflux pumps. Cell Calcium. 2017;61:32-43.

26. Sharma V, Noriega CE, Rowe JJ. Involvement of NarK1 and NarK2 proteins in transport of nitrate and nitrite in the denitrifying bacterium Pseudomonas aeruginosa PAO1. Appl Environ Microbiol. 2006;72:695-701.

27. Jo JTH, Brinkman FSL, Hancock REW. Aminoglycoside efflux in Pseudomonas aeruginosa: involvement of novel outer membrane proteins. Antimicrob Agents Chemother. 2003;47:1101-11.

28. Skindersoe ME, Alhede M, Phipps R, Yang L, Jensen PO, Rasmussen TB, et al. Effects of antibiotics on quorum sensing in Pseudomonas aeruginosa. Antimicrob Agents Chemother. 2008:52:3648-63.

29. Zhu Y, Czauderna T, Zhao J, Klapperstueck M, Maifiah MHM, Han M-L, et al. Genome-scale metabolic modeling of responses to polymyxins in Pseudomonas aeruginosa. Gigascience. 2018;7.

30. Roundtree IA, Evans ME, Pan T, He C. Dynamic RNA modifications in gene expression regulation. Cell. 2017;169:1187-200. https://doi.org/10.1016/..cell. 2017.05.045.

31. Li S, Jin H, Zhang Q. The effect of exogenous spermidine concentration on polyamine metabolism and salt tolerance in Zoysiagrass (Zoysia japonica 
Steud) subjected to short-term salinity stress. Front Plant Sci. 2016;7:1221. https://doi.org/10.3389/fpls.2016.01221.

32. Liu HP, Dong BH, Zhang YY, Liu ZP, Liu YL. Relationship between osmotic stress and the levels of free, conjugated and bound polyamines in leaves of wheat seedlings. Plant Sci. 2004;166:1261-7. https://doi.org/10.1016/J.PLANTSCI.2003.12.039.

33. Li J, Hu L, Zhang L, Pan X, Hu X. Exogenous spermidine is enhancing tomato tolerance to salinity-alkalinity stress by regulating chloroplast antioxidant system and chlorophyll metabolism. BMC Plant Biol. 2015;15: 303. https://doi.org/10.1186/s12870-015-0699-7.

34. Johnson L, Mulcahy H, Kanevets U, Shi Y, Lewenza S. Surface-localized spermidine protects the Pseudomonas aeruginosa outer membrane from antibiotic treatment and oxidative stress. J Bacteriol. 2012;194:813-26. https://doi.org/10.1128/JB.05230-11.

35. Lou Y-C, Weng T-H, Li Y-C, Kao Y-F, Lin W-F, Peng H-L, et al. Structure and dynamics of polymyxin-resistance-associated response regulator PmrA in complex with promoter DNA. Nat Commun. 2015;6:8838.

36. Mulcahy H, O'Callaghan J, O'Grady EP, Maciá MD, Borrell N, Gómez C, et al. Pseudomonas aeruginosa RsmA plays an important role during murine infection by influencing colonization, virulence, persistence, and pulmonary inflammation. Infect Immun. 2008;76:632-8.

37. Allsopp LP, Wood TE, Howard SA, Maggiorelli F, Nolan LM, Wettstadt S, et al. RsmA and AmrZ orchestrate the assembly of all three type $\mathrm{VI}$ secretion systems in Pseudomonas aeruginosa. Proc Natl Acad Sci U S A. 2017;114:7707-12.

38. Romero M, Silistre H, Lovelock L, Wright VJ, Chan K-G, Hong K-W, et al. Genome-wide mapping of the RNA targets of the Pseudomonas aeruginosa riboregulatory protein RsmN. Nucleic Acids Res. 2018.

39. Burrowes E, Baysse C, Adams C, O'Gara F. Influence of the regulatory protein RsmA on cellular functions in Pseudomonas aeruginosa PAO1, as revealed by transcriptome analysis. Microbiology. 2006;152:405-18.

40. Zoued A, Durand E, Bebeacua C, Brunet YR, Douzi B, Cambillau C, et al. TssK is a trimeric cytoplasmic protein interacting with components of both phage-like and membrane anchoring complexes of the type VI secretion system. J Biol Chem. 2013;288:27031-41.

41. Lin J, Cheng J, Chen K, Guo C, Zhang W, Yang X, et al. The icmF3 locus is involved in multiple adaptation- and virulence-related characteristics in Pseudomonas aeruginosa PAO1. Front Cell Infect Microbiol. 2015;5:70,

42. Yang H, Shan Z, Kim J, Wu W, Lian W, Zeng L, et al. Regulatory role of PopN and its interacting partners in type III secretion of Pseudomonas aeruginosa. J Bacteriol. 2007;189:2599-609.

43. Sun Y, Karmakar M, Taylor PR, Rietsch A, Pearlman E. ExoS and ExoT ADP ribosyltransferase activities mediate Pseudomonas aeruginosa keratitis by promoting neutrophil apoptosis and bacterial survival. J Immunol. 2012;188: 1884-95.

44. Rangel SM, Diaz MH, Knoten CA, Zhang A, Hauser AR. The role of ExoS in dissemination of Pseudomonas aeruginosa during pneumonia. PLoS Pathog. 2015;11:e1004945.

45. Li K, Xu C, Jin Y, Sun Z, Liu C, Shi J, et al. SuhB is a regulator of multiple virulence genes and essential for pathogenesis of Pseudomonas aeruginosa. MBio. 2013;4:e00419-3.

46. Pumirat P, Cuccui J, Stabler RA, Stevens JM, Muangsombut V, Singsuksawat E, et al. Global transcriptional profiling of Burkholderia pseudomallei under salt stress reveals differential effects on the Bsa type III secretion system. BMC Microbiol. 2010;10:171.

47. Häussler S, Becker T. The Pseudomonas quinolone signal (PQS) balances life and death in Pseudomonas aeruginosa populations. PLoS Pathog. 2008:4: e1000166. https://doi.org/10.1371/journal.ppat.1000166.

48. Sévin DC, Stählin JN, Pollak GR, Kuehne A, Sauer U. Global metabolic responses to salt stress in fifteen species. PLoS One. 2016;11:e0148888.

49. Kilstrup M, Jacobsen S, Hammer K, Vogensen FK. Induction of heat shock proteins DnaK, GroEL, and GroES by salt stress in Lactococcus lactis. Appl Environ Microbiol. 1997;63:1826-37.

50. García-Descalzo L, Alcazar A, Baquero F, Cid C. Identification of in vivo HSP90-interacting proteins reveals modularity of HSP9O complexes is dependent on the environment in psychrophilic bacteria. Cell Stress Chaperones. 2011;16:203-18.

51. Vallet-Gely I, Sharp JS, Dove SL. Local and global regulators linking anaerobiosis to cupA fimbrial gene expression in Pseudomonas aeruginosa. J Bacteriol. 2007;189:8667-76

52. Hilker M, Schwachtje J, Baier M, Balazadeh S, Bäurle I, Geiselhardt S, et al. Priming and memory of stress responses in organisms lacking a nervous system. Biol Rev Camb Philos Soc. 2015. https://doi.org/10.1111/brv.12215.
53. Molassiotis A, Tanou G, Diamantidis G. NO says more than "YES" to salt tolerance: salt priming and systemic nitric oxide signaling in plants. Plant Signal Behav 2010;5:209-212. http://www.ncbi.nlm.nih.gov/pubmed/ 20061805. Accessed 26 Jun 2018.

54. Ibrahim EA. Seed priming to alleviate salinity stress in germinating seeds. J Plant Physiol. 2016;192:38-46. https://doi.org/10.1016/j.jplph.2015.12.011.

55. Conrath U, Beckers GJM, Flors V, García-Agustín P, Jakab G, Mauch F, MA Newman, Pieterse CMJ, Poinssot B, Pozo MJ, Pugin A, Schaffrath U, Ton J, Wendehenne D, Zimmerli L, Mauch-Mani B. Priming: getting ready for battle. Mol Plant Microbe Interact. 2006;19(10):1062-71.

56. Bruce TJA, Pickett JA. Plant defence signalling induced by biotic attacks. Curr Opin Plant Biol. 2007;10(4):387-92.

57. Lambert G, Kussell E, Matic I. Memory and fitness optimization of bacteria under fluctuating environments. PLoS Genet. 2014;10(9):e1004556.

58. Seemann T. Prokka: rapid prokaryotic genome annotation. Bioinformatics. 2014;30(14):2068-9.

59. Seemann T. Snippy: fast bacterial variant calling from NGS reads. 2015. https://github.com/tseemann/snippy.

60. Smyth GK. Linear models and empirical bayes methods for assessing differential expression in microarray experiments. Stat Appl Genet Mol Biol. 2004;3:Article3. https://doi.org/10.2202/1544-6115.1027.

61. Smyth GK, Speed T. Normalization of CDNA microarray data. Methods. 2003; 31(4):265-73.

62. Mi H, Huang $X$, Muruganujan A, Tang H, Mills C, Kang D, Thomas PD. PANTHER version 11: expanded annotation data from Gene Ontology and Reactome pathways, and data analysis tool enhancements. Nucleic Acids Res. 2017:45(D1):D183-D189.

63. Huntley RP, Binns D, Dimmer E, Barrell D, O'Donovan C, Apweiler R. QuickGO: a user tutorial for the web-based Gene Ontology browser. Database 2009.

64. Liberati NT, Urbach JM, Miyata S, Lee DG, Drenkard E, Wu G, Villanueva J, Wei T, Ausubel FM. An ordered, nonredundant library of Pseudomonas aeruginosa strain PA14 transposon insertion mutants. Proceedings of the National Academy of Sciences. 2006;103(8):2833-8.

65. Sprouffske K, Wagner A. Growthcurver: an R package for obtaining interpretable metrics from microbial growth curves. BMC Bioinforma. 2016;17(1).

66. R Core Team. R: a language and environment for statistical computing. Vienna, Austria: R Foundation for Statistical Computing; 2015.

\section{Publisher's Note}

Springer Nature remains neutral with regard to jurisdictional claims in published maps and institutional affiliations.
Ready to submit your research? Choose BMC and benefit from:
- fast, convenient online submission
- thorough peer review by experienced researchers in your field
- rapid publication on acceptance
- support for research data, including large and complex data types
- gold Open Access which fosters wider collaboration and increased citations
- maximum visibility for your research: over $100 \mathrm{M}$ website views per year
At BMC, research is always in progress.
Learn more biomedcentral.com/submissions 